\title{
Using the TAM Model to Predict Undergraduate Distance Learners Behavioural Intention to Use the Makerere University Learning Management System
}

\author{
Susan Kasula Munabi ${ }^{*}$, Jessica Aguti $^{2}$, Harriet Mutambo Nabushawo ${ }^{2}$ \\ ${ }^{1}$ Department of Adult and Community Education, School of Distance and Lifelong Learning, Makerere University College of \\ Education and External Studies, Kampala, Uganda \\ ${ }^{2}$ Department of Open, Distance and E-Learning, School of Distance and Lifelong Learning, Makerere University College of \\ Education and External Studies, Kampala, Uganda \\ Email: ^susan.kasula@gmail.com, jnaguti@gmail.com, hnabushawo@gmail.com
}

How to cite this paper: Munabi, S.K., Aguti, J. and Nabushawo, H.M. (2020) Using the TAM Model to Predict Undergraduate Distance Learners Behavioural Intention to Use the Makerere University Learning Management System. Open Access Library Journal, 7: e6699.

https://doi.org/10.4236/oalib.1106699

Received: August 8, 2020

Accepted: September 21, 2020

Published: September 24, 2020

Copyright $\odot 2020$ by author(s) and Open Access Library Inc.

This work is licensed under the Creative Commons Attribution International License (CC BY 4.0).

http://creativecommons.org/licenses/by/4.0/

(c) (i) Open Access

\begin{abstract}
The purpose of the research was to predict the factors that affect the undergraduate distance learners behavioural intention to use the Makerere University E-learning Environment (MUELE) at Makerere university using the Learning Management System-Technology Acceptance Model (LMS-TAM). The LMS-TAM used for this study, was made up of the three factors from original Technology Acceptance Model (TAM): perceived ease of use, perceived usefulness, and behavioural intention including an external factor called enjoyment. It involved distribution of self-administered validated questionnaires to 114 students. A Partial least squares structural equation modeling approach was used to analyse the data captured by the study questionnaire. The model predicted that enjoyment and perceived usefulness were the factors that influenced learners' continued use of the LMS. These findings were significant with enjoyment having a greater effect $(0.85)$ on behavioural intention than perceived usefulness with an effect of $(0.40)$. This information can be utilised in the design of interventions that increase learners' use of the learning management system.
\end{abstract}

\section{Subject Areas}

Education, Information Science

\section{Keywords}

Learning Management System-Technology Acceptance Model, LMS-TAM, Structural Equation Modeling, Distance learners 


\section{Introduction}

The worldwide growth in numbers of prospective learners is a challenge to the currently available educational infrastructure [1] [2] [3]. This challenge is most pronounced in developing countries that, in addition to high population growth rates, are unable to cover the costs of building more classrooms or increase the resources needed to address the United Nations fourth Sustainable Development Goal, on ensuring inclusive and equitable quality education and promote lifelong learning opportunities for all. Delivering Distance Education through online learning, using Learning Management System's (LMS's), has been identified as one of the strategies for the attainment of this goal [4]. Emergencies such as the COVID-19 pandemic that has led to closure of schools and universities have reinforced the need for distance education to ensure that teaching and learning continues [5].

The resistance by faculty and students to the use of the learning management system (LMS) has led to research and development of models around the acceptance of LMS in Sub-Saharan Africa [6] [7]. The Technology Acceptance Model (TAM), which is grounded in the theory of reasoned action, uses people's behaviour to predict whether they will accept and or adopt, use of technologies like the LMS [8]. A literature review conducted by Bervell and Umar (2017) [6] in sub-Saharan Africa, revealed that there was a limited number of Technology acceptance research studies in the use of the LMS with existing data from only 7 countries. Information from Uganda cited studies from two relatively new universities: from Mbarara University [9] and from Muni University [10], while Makerere University the oldest and largest university in Uganda was missing. Further information also showed that neither of these studies used the TAM nor did any of them used the recommended structural equation modeling approach for Learning Management System-Technology Acceptance Model [11].

\section{Review of Literature}

The Learning management systems (LMSs) are used mostly to support the delivery of teaching and learning by institutions of higher learning. Moodle, is one of the opens source LMSs that can obtained freely while the commercial LMS involves payment of licence fees [12]. According to the study by Bervell and Umar (2017) [6], acceptance and adoption research evolved as a result of studying the behaviour of users towards a particular technology with the aim of maintaining continued use of the technology [6]. This eventually led to the development of models informed by multiple theories on the acceptance of a technology. One of the theories informing the Technology Acceptance Model (TAM), is the theory of reasoned action that deals with studying behaviour in order to explain the use of a technology. The original TAM was composed of three factors that directly and indirectly affected behavioural intention (BI perceived ease of use, perceived usefulness and attitude [13]. A study by Ziraba et al. (2020) [12] showed that these factors: perceived ease of use and perceived usefulness are very important in the adoption and use of an LMS. More recently, 
the original TAM was modified to make the Learning Management System-TAM by Findik-Coşkunçay et al. (2018) [8], with the addition of four external factors: subjective norm, enjoyment, satisfaction and interactivity and control including two internal factors: perceived ease of use and perceived usefulness. The current push to use e-learning with the ongoing COVID-19 pandemic, has forced many universities all over the world to change to online delivery of education [14] [15] [16]. Availability of information on the technology acceptance is especially critical to guide institutional change from face to face delivery to online teaching. There is a limited number of Technology Acceptance research studies in Sub-Saharan Africa in the area of the LMS with only data available from 7 out of the 48 countries [6]. The objective of this study was to use the LMS-TAM to predict the factors that affect the undergraduate distance learners behavioural intention to use the Makerere University E-learning Environment (MUELE) at Makerere university using the Learning Management System-Technology Acceptance Model (LMS-TAM).

\section{Methods}

This was a survey of students on the Bachelor of Commerce External, Distance Education programme at Makerere University using a quantitative data approach founded on the positivist paradigm. The survey was conducted at Makerere University in the academic year, 2018/2019 during the students face to face session on campus. The survey involved the use of a self-administered questionnaire on both the first and second year B. Com External university registered students. The inclusion criteria for participation was a willingness to take part in the study. Students who were not reachable at the time of data collection were excluded from the study. The minimum sample was calculated using an online calculator for structural equation modeling by Soper (2018) [17] where alpha represented level of significance of 0.05 while beta represented power level of $80 \%$, in a model with four latent variables: perceived usefulness (PU), perceived ease of use (PE) behavioural intention (BI) and enjoyment (ENJ). PU is the extent to which the learner believes their performance in their studies will improve, when they use the LMS, while PE is the extent to which the learner believes when they use the LMS, they do so effortlessly. Enjoyment (ENJ) implies that using the LMS is perceived as enjoyable to the learner while behavioural intention (BI) is when an individual consciously makes a decision to use the LMS. Table 1 presents the demographic profile of the sample.

\section{Questionnaire}

The self-administered questionnaire used in this study was adapted from previously used LMS-TAM instruments from other studies on university student populations [8] [18]. From the original LMS-TAM, in the study by Findik-Coşkunçay et al. (2018) [8] there were 44 indicators overall. For this study only 16 indicators with high factor loading scores of 0.7 and above shown in the study by Findik-Coşkunçay et al. (2018) [8] were selected. The indicators used in the ques- 
tionnaire are formulated around each of the four latent variables: Enjoyment (ENJ) had 4 indicators, Perceived usefulness (PU) had four indicators, Perceived ease of use (PE) had five indicators and behavioural intention (BI) had 3 indicators as shown in Figure 1.

In this study the following hypotheses were tested:

H1: Perceived usefulness directly and positively affects Behavioural intention $(B I)$.

H2: Perceived ease of use directly and positively affects Behavioural intention $(B I)$.

H3: Enjoyment directly and positively affects Behavioural intention (BI).

Pre-testing of data collection tools was done with 10 people: 5 first year students and 5 second year students and their feedback was used to further refine the final tool. Student leaders were then engaged to participate in the process of collecting completed questionnaires from the student respondents. All returned questionnaires were reviewed for completeness before double data entry into a database, developed using Epidata version 3.1 software.

Table 1. Demographic information of the study population.

\begin{tabular}{cc}
\hline Variable & No of Respondents (Percentage) \\
\hline Sex & $68(60)$ \\
Male & $45(39)$ \\
Female & $1(1)$ \\
Missing & $114(100)$ \\
Total & \\
Year of Enrolment & $98(86)$ \\
First & $14(12)$ \\
Second & $2(2)$ \\
Missing & $114(100)$ \\
Total
\end{tabular}

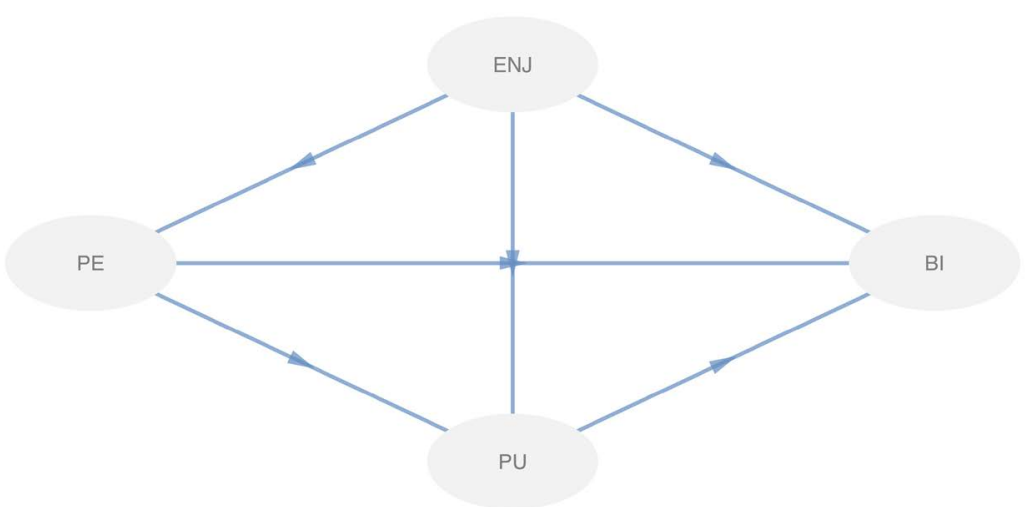

Figure 1. Summarising the study model and the constructs (The constructs are: Enjoyment (ENJ), Perceived usefulness (PU), Perceived ease of use (PE) and behavioural intention (BI)). 


\section{Analysis}

The validated data set was exported as a csv file to $\mathrm{R}$ statistical computing environment for analysis [19]. Partial least squares structural equation modeling using the PLS-PM package by Sanchez (2013) [20], was used in R statistical computing environment to generate metrics of a model which predicted the students' behavioural intention to use MUELE ICT support. The measured variables were modelled using mode A (reflective) to each latent variable. Since partial least squares path modeling does not follow any distribution, the identified significant paths and effects were based on bootstrapping output after 15,000 boot replications. If the confidence interval of a path coefficient included zero, then it is not statistically significant. Results of the predictive structural equation modeling were presented using the PLSPM reporting guidelines in two steps, analysis of reflective measurement model and analysis of structural model [11]. Records with missing data were excluded from the analysis. Approval was sought through presentation before a team of lecturers in the School of Distance and Lifelong Learning. All research participants provided informed consent before they enrolled in the study. Throughout the study, the confidentiality of the data was upheld by using unique identifiers to make the data anonymous. Only the principal researcher had access to the data.

\section{Results}

A total of 114 self-administered questionnaires were returned by participants who voluntarily agreed to participate in the study. The respondents consisted of 68 males (60\%) and 45 females (39\%). There were 98 (86\%) respondents who were first year students and $14(12 \%)$ who were second year students. Table 2 is a summary of the responses to the questions used in the tool and shows each construct and the corresponding items or indicators. The indicators were scored on a Likert scale from 1 to 5 representing "Strongly disagree", "Disagree", "Neutral", "Agree" and "Strongly Agree" and the median as shown in Table 2. Records with missing data were excluded from the analysis leaving a total of 84 complete records for further structural equation modeling which was above the minimum sample size to detect effect of 77 respondents.

\section{The analysis of the reflective measurement model}

The model was found to be reliable and valid. This was shown using the following measures: reliability of indicators, internal consistent reliability, convergent validity and discriminant validity. The results of the analysis for reflective measurement model are shown in Tables 2-4. Reliable indicators are those whose construct explains over $50 \%$ of the indicator variance. The values of indicator loadings shown in Table 2, were all above the minimum threshold of 0.7 [11]. This confirms the reliability of the indicators. Internal consistent reliability, was shown using the values for Cronbach alpha and composite reliability. Each of the constructs in Table 3, met the recommended minimum threshold of 0.7 and less than the maximum threshold of 0.95 . In addition, it's important to note that the composite reliability value for the construct behavioural intention was 0.946 
Table 2. Summary of questionnaire tool used in this study.

\begin{tabular}{|c|c|c|c|c|}
\hline Constructs & & Measurement instrument & Mediar & Loading \\
\hline \multirow{4}{*}{ Enjoyment (ENJ) } & F14 & I find it enjoyable to use MUELE. & 2.00 & 0.89 \\
\hline & F15 & I find it interesting to use MUELE. & 2.00 & 0.92 \\
\hline & F16 & MUELE is a fun activity. & 2.00 & 0.80 \\
\hline & F17 & The use of MUELE arouses my curiosity. & 2.00 & 0.87 \\
\hline \multirow{5}{*}{$\begin{array}{c}\text { Perceived } \\
\text { Ease-of-Use (PE) }\end{array}$} & $\mathrm{F} 4$ & It is easy for me to learn to navigate the MUELE system. & 2.00 & 0.85 \\
\hline & F5 & I am skilful at using the MUELE system. & 2.00 & 0.85 \\
\hline & F11 & $\begin{array}{l}\text { I am confident of using MUELE even if there is no one } \\
\text { around to show me how to do it. }\end{array}$ & 2.00 & 0.88 \\
\hline & F12 & $\begin{array}{l}\text { I am confident of using MUELE even if I do not have } \\
\text { an online manual for reference. }\end{array}$ & 2.00 & 0.87 \\
\hline & F13 & $\begin{array}{l}\text { I am confident of using MUELE even if I do not watch } \\
\text { someone use it before trying it myself. }\end{array}$ & 2.00 & 0.89 \\
\hline \multirow{4}{*}{$\begin{array}{c}\text { Perceived } \\
\text { Usefulness (PU) }\end{array}$} & $\mathrm{F} 1$ & Using MUELE improves my performance in courses. & 2.00 & 0.92 \\
\hline & $\mathrm{F} 2$ & MUELE is useful to follow course activities online. & 3.00 & 0.84 \\
\hline & F3 & MUELE improves my success in courses. & 2.00 & 0.89 \\
\hline & F22 & $\begin{array}{l}\text { MUELE allows controlling the learning sequence. } \\
\text { (Proper flow of content i.e. from easy to hard) }\end{array}$ & 2.50 & 0.75 \\
\hline \multirow{3}{*}{$\begin{array}{l}\text { Behavioural } \\
\text { Intention (BI) }\end{array}$} & F8 & $\begin{array}{l}\text { If courses are supported with MUELE, I intend to use it } \\
\text { frequently. }\end{array}$ & 2.00 & 0.94 \\
\hline & F9 & I think the instructors should support the use of MUELE. & 2.00 & 0.91 \\
\hline & F10 & I think the instructors should continue to use MUELE. & 2.00 & 0.93 \\
\hline
\end{tabular}

Table 3. Performance measures of the model.

\begin{tabular}{ccccc}
\hline Latent variables & ENJ & PE & PU & BI \\
\hline Composite reliability (DG.rho) & 0.92 & 0.94 & 0.90 & 0.95 \\
Cronbach alpha & 0.88 & 0.92 & 0.85 & 0.92 \\
Average Variance Extracted & 0.76 & 0.76 & 0.72 & 0.86 \\
eig.1st & 2.94 & 3.78 & 2.79 & 3.37 \\
eig.2nd & 0.47 & 0.52 & 0.69 & 0.27 \\
Redundancy $\left(\mathrm{Q}^{2}\right)$ & 0.00 & 0.52 & 0.52 & 0.68 \\
$\mathrm{R}^{2}$ & 0.00 & 0.69 & 0.66 & 0.79 \\
VIF $\left(1 /\left(1-\mathrm{R}^{2}\right)\right)$ & & 3.23 & 2.94 & 4.76 \\
Latent variables correlations & & & & \\
Latent variables & ENJ & PE & PU & BI \\
ENJ & 1.00 & 0.83 & 0.77 & 0.85 \\
PE & 0.83 & 1.00 & 0.78 & 0.80 \\
PU & 0.77 & 0.78 & 1.0 & 0.83 \\
BI & 0.85 & 0.80 & 0.83 & 1.00 \\
\hline
\end{tabular}


Table 4. The Heterotrait-monotrait ratio (HTMT).

\begin{tabular}{ccccc}
\hline Latent variables & ENJ & PE & PU & BI \\
\hline ENJ & 0.00 & 0.00 & 0.00 & 0.00 \\
PE & 0.91 & 0.00 & 0.00 & 0.00 \\
PU & 0.87 & 0.87 & 0.00 & 0.00 \\
BI & 0.91 & 0.81 & 0.91 & 0.00 \\
\hline
\end{tabular}

which is still below the mentioned threshold of 0.95 . This confirms internal consistent reliability. Convergent validity is defined as the extent to which a construct converges to explain the variance of its items. To assess convergent validity, the value of average variance extracted (AVE) for all latent variables was assessed and passed the minimum threshold of 0.5 as shown in Table 3 . This shows that the construct explains more than $50 \%$ of the item's variance [11]. This confirms convergent validity.

According to Hair et al. (2019) [11], discriminant validity is the extent to which a construct is different from other constructs. This was revealed by the value of the heterotrait-monotrait (HTMT) ratio of the correlations shown in Table 4 . The values are less than 1.0 as recommended by [21]. This confirms discriminant validity.

\section{Analysis of the structural model}

The assessment of the structural model involved testing for collinearity, predictive power of the model and assessment of statistical significance of the hypothesized paths. The results of the structural model are shown in Table 5, Table 6 and Figure 2. Collinearity is the correlation between independent variables and if it's high, this can cause troubles with fitting the model and interpreting results [11]. Collinearity is measured by the value of variance inflation factor (VIF) and these values were less than the recommended threshold of 5 as shown in Table 3. Therefore, this confirmed that collinearity issues were not likely to happen. The coefficient of determination $\left(\mathrm{R}^{2}\right)$, is defined by Hair et al. (2019) [11] as the in-sample predictive power of the model. The $\mathrm{R}^{2}$ value for behavioural intention, was 0.79 as shown in Table 3 . This means that the model predicted behavioural intention for $79 \%$ of the students in this study. It was shown to have good prediction power.

\section{Assessing statistical significance of hypothesized paths}

Bootstrapping procedures were used to assess statistical significance of hypothesized path coefficients. If the confidence interval of a path coefficient included zero, then it was not statistically significant [11]. Looking at the bootstrap confidence intervals shown in Table 5, Perceived usefulness (0.19 to 0.59) and enjoyment ( 0.23 to 0.78 ) had significant and positive effects on behavioural intention since the confidence interval did not contain zero (0). In contrast, confidence interval for Perceived ease of use $(-0.18$ to 0.30$)$ was insignificantly related to $\mathrm{BI}$ as the confidence interval contained a zero. This led to support of hypotheses (H1: PU directly and positively affects BI, and H3: ENJ directly and positively affects BI) and no statistical support for hypothesis (H2: PE directly 
and positively affects BI). According to the article by Hair et al. (2019) [11] value of total effect was used to compare the two factors that had the most significant influence on behavioural intention of the learners to use the LMS. Enjoyment had a larger effect (0.85) compared to Perceived usefulness with effect (0.40) as shown in Table 6. Thus, Enjoyment was a greater predictor of behavioural intention, followed by perceived usefulness.

Figure 2 shows a pictorial summary of paths and corresponding coefficients connecting the different latent variables in the structural part of the model.

Table 5. Showing the structural models' path regression and boot-strap results.

\begin{tabular}{ccccccccc}
\hline & \multicolumn{5}{c}{ Regression results } & \multicolumn{5}{c}{ Bootstrap results (br =15,000) } \\
\hline Latent variables & Estimate & Std. Error & $\mathrm{t}$ value & $\operatorname{Pr}(>|\mathrm{t}|)$ & Mean & Std.err & $95 \% \mathrm{~B}$-Ca & Accept \\
\hline BI & & & & & & & & \\
Intercept & $<-0.01$ & 0.05 & $<-0.01$ & 1.00 & & & & \\
ENJ & 0.51 & 0.10 & 5.26 & $<0.01$ & 0.51 & 0.14 & 0.23 to 0.78 & Yes \\
PE & 0.03 & 0.10 & 0.29 & 0.77 & 0.04 & 0.12 & -0.18 to 0.30 & No \\
PU & 0.40 & 0.09 & 4.65 & $<0.01$ & 0.39 & 0.10 & 0.19 to 0.59 & Yes \\
PE & & & & & & & & \\
Intercept & $<-0.01$ & 0.06 & $<-0.01$ & 1.00 & & & & \\
ENJ & 0.83 & 0.06 & 1.35 & $<0.01$ & 0.85 & 0.04 & 0.77 to 0.92 & Yes \\
PU & & & & & & & & \\
Intercept & $<-0.01$ & 0.07 & $<-0.01$ & 1.00 & & & & \\
ENJ & 0.41 & 0.12 & 3.48 & $<0.01$ & 0.41 & 0.15 & 0.12 to 0.71 & Yes \\
PE & 0.44 & 0.12 & 3.79 & $<0.01$ & 0.46 & 0.15 & 0.16 to 0.75 & Yes \\
\hline
\end{tabular}

Table 6. Showing a summary of the effects for each hypothesized path in the model.

\begin{tabular}{|c|c|c|c|c|c|c|}
\hline \multirow[b]{2}{*}{ Hypothesis } & \multirow[b]{2}{*}{ Relationships } & \multicolumn{3}{|c|}{ Original effects } & \multicolumn{2}{|c|}{ Bootstrap results } \\
\hline & & direct & indirect & total & $95 \% \mathrm{~B}-\mathrm{Ca}$ & Accept \\
\hline H3 & enjoyment -> behavioral.intention & 0.51 & 0.34 & 0.85 & 0.23 to 0.78 & Yes \\
\hline $\mathrm{H} 2$ & perceived.ease.of.use -> behavioral.intention & 0.03 & 0.18 & 0.21 & -0.18 to 0.30 & No \\
\hline $\mathrm{H} 1$ & perceived.usefulness $->$ behavioral.intention & 0.40 & 0.00 & 0.40 & 0.19 to 0.59 & Yes \\
\hline
\end{tabular}

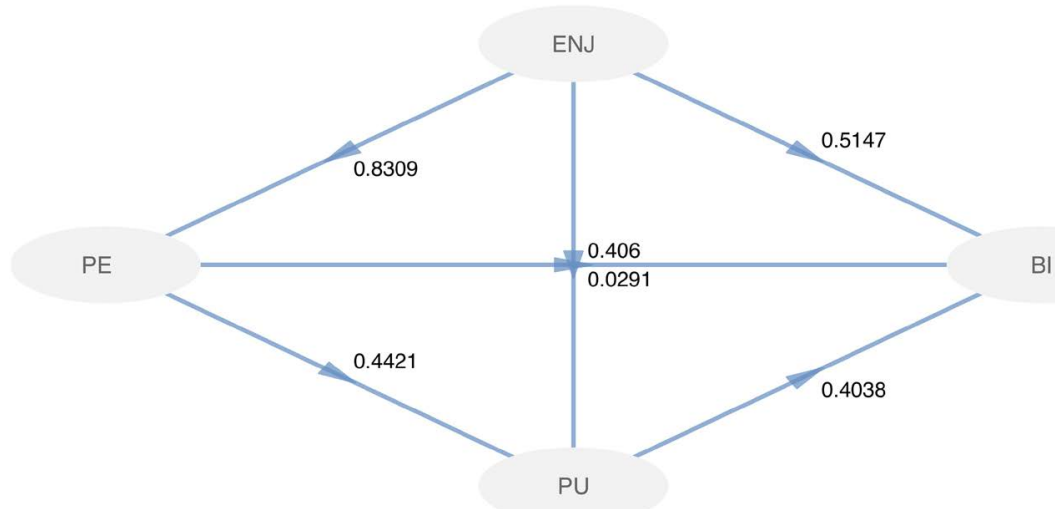

Figure 2. Validated structural model showing direct effects (All paths are significant except one path: perceived ease of use to behavioural intention). 


\section{Discussion}

Structural equation modeling analysed the relationships among the following constructs perceived ease of use, perceived usefulness, behavioural intention and enjoyment. This study tested three hypotheses and only two hypotheses $\mathrm{H} 1$ and $\mathrm{H} 3$ were statistically supported. Where $\mathrm{H} 1$ states that: Perceived usefulness directly and positively affects Behavioural intention; H3 states that: Enjoyment directly and positively affects Behavioural Intention. H2 was not statistically supported, where $\mathrm{H} 2$ states that: perceived ease of use directly and positively affects behavioural intention. The greatest predictor of behavioural intention was enjoyment followed by perceived usefulness.

The results showed that perceived usefulness significantly influences behavioural intention of learners. This means that once the distance learners perceive the LMS to be useful, then they are more likely to increase their use of the LMS. This finding is similar to the one in the study by [8] [22]. According to B.-C. Lee, Yoon, \& Lee, 2009 [23] usefulness of the LMS is two way, which implies that the LMS is designed and developed to be of worth to the learner and also occasionally adding value to the LMS. Results demonstrated that perceived ease of use significantly influences perceived usefulness. This means when learners find the learning management system easy to use they are more likely to feel that it is useful to them. This finding was supported by the study by [8] [13]. According to Mtebe \& Kissaka (2015) [24] learners in developing countries are more likely to find the LMS useful when the design and content is easy to read, use and learn.

The results also showed that Enjoyment significantly influences behavioural intention of distance learners to use the LMS. Enjoyment also has a significant effect on both perceived ease of use and perceived usefulness. This means that once the distance learners enjoy and have fun through their experience while using the LMS, they are more likely to keep using the LMS. This finding is supported by [8] [22]. Since enjoyment plays a key role in both learner's perceived ease of use and perceived usefulness of the LMS, according to Findik-Coşkunçay et al. (2018) [8], enjoyment is seen to play a key role in the use of and acceptance of technologies. Therefore, lecturers should provide the learners an environment where they have fun, curiosity is aroused as learners interact with content and receive timely feedback from the lecturers.

Lastly, the results showed that perceived ease of use does not significantly affects behavioural intention. This finding is similar to that of the original TAM where perceived ease of use does not directly influence the behavioural interaction [13]. In contrast to the findings in this study, these studies by Findik-Coşkunçay et al. (2018) [8] and Y.-C. Lee (2008) [25] showed that perceived ease of use significantly and positively affects behavioural intention. This finding means that most of the students do not perceive the system as easy to use and are likely not to use the system. According to Ssekakubo, Suleman, and Marsden (2011) [26], this could be because learners lack the skills to use the LMS. Training of learners to use the LMS efficiently is therefore necessary. 


\section{Limitations}

The respondents in this study were students from the same university, which may not fully represent the views of other distance learners from other universities. To improve the generalisation of results, this study can be carried out in other universities by another sample of students.

\section{Further suggestions}

This study only focused on perceptions of learners, however other studies can focus on perceptions of instructors or administrators. This was a cross-sectional quantitative study, there is a need for qualitative research such as in-depth interviews to provide more detailed information about the relationships among the constructs.

\section{Conclusion and Recommendations}

This study revealed that the Technology Acceptance Model (TAM) is relevant in predicting factors that influence undergraduate distance learners behavioural intention to use the learning management system-Makerere University E-learning Environment at Makerere University. These factors are related to perceptions of the learners: perceived ease of use, perceived usefulness, enjoyment and behavioural intention. The LMS-TAM model was validated and predicted that enjoyment and perceived usefulness directly influence the learner's behavioural intention to use of the Learning management system. When the LMS Increases enjoyment and perceived usefulness it is most likely to be accepted. These findings showed that enjoyment had a greater effect $(0.85)$ on behavioural intention than perceived usefulness with an effect of (0.40). This information can be utilised by researchers, those in decision making and those involved in design to increase the use of learning management systems. Although this study was done before COVID-19 pandemic outbreak, the findings remain relevant for the ongoing implementation of the e-learning interventions in response to the pandemic.

\section{Conflicts of Interest}

The authors declare no conflicts of interest regarding the publication of this paper.

\section{Acknowledgements}

The authors would like to thank all students who participated in this study for their valuable contribution.

\section{References}

[1] Bacci, M.L. (2017) A Concise History of World Population. John Wiley \& Sons, Hoboken.

[2] Khaitsa, M., Lumutenga, N.W., Muwazi, R., Wakoko-Studstill, F., Naigaga, I., Sengendo, M., Kanabahita, K., et al. (2017) Higher Education Resource Services, 
East Africa: A Women Leadership and Management Development Model. Pan African Medical Journal, 7, 12269.

[3] Mutambo, N.H., Aguti, J.N. and Winterbottom, M.H. (2018) Effectiveness of Study Centres in Supporting Open and Distance Learning at Makerere University. Makerere Journal of Higher Education, 10, 45-59.

[4] Rajesh, M., Nair, S.P. and JalajaKumari, V. (2018) Integrating Digital Learning Management System (LMS) into Institutional Policies on Open Education in India for the Attainment of Sustainable Development Goals (SDGs). In: Optimizing Open and Distance Learning in Higher Education Institutions, IGI Global, Hershey, 292-312. https://doi.org/10.4018/978-1-5225-2624-7.ch014

[5] Mukeredzi, T., Kokutse, F. and Dell, S. (2020) Student Bodies Say e-Learning Is Unaffordable and Elitist.

https://www.universityworldnews.com/post.php?story=20200422075107312

[6] Bervell, B. and Umar, I. (2017) A Decade of LMS Acceptance and Adoption Research in Sub-Sahara African Higher Education: A Systematic Review of Models, Methodologies, Milestones and Main Challenges. Eurasia Journal of Mathematics, Science and Technology Education, 13, 7269-7286.

https://doi.org/10.12973/ejmste/79444

[7] Sackstein, S., Coleman, E. and Ndobe, T.V. (2019) Lecturers' Perceptions of Learning Management Systems within a Previously Disadvantaged University. In: Opening up Education for Inclusivity across Digital Economies and Societies, IGI Global, Hershey, 1-28. https://doi.org/10.4018/978-1-5225-7473-6.ch001

[8] Findik-Coşkunçay, D., Alkiş, N. and Özkan-Yildirim, S. (2018) A Structural Model for Students' Adoption of Learning Management Systems: An Empirical Investigation in the Higher Education Context. Journal of Educational Technology \& Society, 21, 13-27. https://doi.org/10.1037/t70573-000

[9] Kabarungi, M., Musiimenta, A. and Atuhe, A. (2016) Impact of e-Learning Management System Adoption at Mbarara University of Science and Technology. International Journal of Emerging Trends \& Technology in Computer Science, 39, 62-65.

[10] Mbabazi, B.P. and Ali, G. (2016) Evaluation of e-Learning Management Systems by Lecturers and Students in Ugandan Universities: A Case of Muni University. International Journal of Innovative Research in Science, Engineering and Technology, 5, 9529.

[11] Hair, J.F., Risher, J.J., Sarstedt, M. and Ringle, C.M. (2019) When to Use and How to Report the Results of PLS-SEM. European Business Review, 31, 2-24. https://doi.org/10.1108/EBR-11-2018-0203

[12] Ziraba, A., Akwene, G.C. and Lwanga, S.C. (2020) The Adoption and Use of Moodle Learning Management System in Higher Institutions of learning: A Systematic Literature Review. American Journal of Online and Distance Learning, 2, 1-21.

[13] Davis, F.D., Bagozzi, R.P. and Warshaw, P.R. (1989) User Acceptance of Computer Technology: A Comparison of Two Theoretical Models. Management Science, 35, 982-1003. https://doi.org/10.1287/mnsc.35.8.982

[14] Almaiah, M.A., Al-Khasawneh, A. and Althunibat, A. (2020) Exploring the Critical Challenges and Factors Influencing the E-Learning System Usage during COVID-19 Pandemic. Education and Information Technologies, 1-20. https://doi.org/10.1007/s10639-020-10219-y

[15] Liguori, E. and Winkler, C. (2020) From Offline to Online: Challenges and Oppor- 
tunities for Entrepreneurship Education Following the COVID-19 Pandemic. SAGE Publications, Los Angeles. https://doi.org/10.1177/2515127420916738

[16] Moorhouse, B.L. (2020) Adaptations to a Face-to-Face Initial Teacher Education Course "Forced" Online Due to the COVID-19 Pandemic. Journal of Education for Teaching, 1-3. https://doi.org/10.1080/02607476.2020.1755205

[17] Soper, D. (2018) A-Priori Sample Size Calculator for Structural Equation Models [Software].

[18] Irinoye, O., Ayamolowo, S. and Tijnai, O.K. (2016) Part-Time Undergraduate Nursing Students' Perception and Attitude to ICT Supports for Distance Education in Nursing in Nigeria. Malaysian Online Journal of Educational Technology, 4, 8-21.

[19] Team, R.C. (2019) R: A Language and Environment for Statistical Computing Computer Program, Version 3.6.1. R Core Team, Vienna.

[20] Sanchez, G. (2013) PLS Path Modeling with R. Trowchez Editions, Berkeley, 383.

[21] Henseler, J., Ringle, C.M. and Sarstedt, M. (2015) A New Criterion for Assessing Discriminant Validity in Variance-Based Structural Equation Modeling. Journal of the Academy of Marketing Science, 43, 115-135. https://doi.org/10.1007/s11747-014-0403-8

[22] Binyamin, S.S., Rutter, M. and Smith, S. (2019) Extending the Technology Acceptance Model to Understand Students' Use of Learning Management Systems in Saudi Higher Education. International Journal of Emerging Technologies in Learning, 14, 4-21. https://doi.org/10.3991/ijet.v14i03.9732

[23] Lee, B.-C., Yoon, J.-O. and Lee, I. (2009) Learners' Acceptance of e-Learning in South Korea: Theories and Results. Computers \& Education, 53, 1320-1329. https://doi.org/10.1016/j.compedu.2009.06.014

[24] Mtebe, J.S. and Kissaka, M.M. (2015) Heuristics for Evaluating Usability of Learning Management Systems in Africa. The 2015 IST-Africa Conference, Lilongwe, 6-8 May 2015, 1-13. https://doi.org/10.1109/ISTAFRICA.2015.7190521

[25] Lee, Y.-C. (2008) The Role of Perceived Resources in Online Learning Adoption. Computers \& Education, 50, 1423-1438. https://doi.org/10.1016/j.compedu.2007.01.001

[26] Ssekakubo, G., Suleman, H. and Marsden, G. (2011) Issues of Adoption: Have e-Learning Management Systems Fulfilled Their Potential in Developing Countries? The Proceedings of the South African Institute of Computer Scientists and Information Technologists Conference on Knowledge, Innovation and Leadership in a Diverse, Multidisciplinary Environment, Cape Town, October 2011, 231-238. https://doi.org/10.1145/2072221.2072248 